\title{
Research on the Deformation Characteristics of Pressure Culvert Linings Based on Monitoring
}

\author{
Liang Jingwei, ${ }^{1}$ Wang Xiang, ${ }^{1}$ Cao Lei $\left(\mathbb{D},{ }^{2}\right.$ and Jiang Chu ${ }^{1}$ \\ ${ }^{1}$ Hunan Institute of Water Resources and Hydropower Research, Changsha 410007, China \\ ${ }^{2}$ School of Water Resources and Hydropower, Hunan Polytechnic of Water Resources and Electric Power, \\ Changsha 410131, China \\ Correspondence should be addressed to Cao Lei; 815172232@qq.com
}

Received 24 December 2021; Accepted 15 January 2022; Published 18 February 2022

Academic Editor: Yu Liang

Copyright (C) 2022 Liang Jingwei et al. This is an open access article distributed under the Creative Commons Attribution License, which permits unrestricted use, distribution, and reproduction in any medium, provided the original work is properly cited.

It is of great significance to study the deformation characteristics of the lining of a long-distance pressure culvert. The lining of a pressure culvert has the characteristics of strong concealment and remarkable influence on the whole performance. The existing research on deformation characteristics mostly adopts nondestructive detection, and the accuracy is restricted by many factors. In this paper, the lining of a pressure culvert is taken as the research object, and in situ tests of the structure are carried out and numerical simulations are conducted. Based on field monitoring data, the mechanical and deformation responses of the lining structure under external water and earth pressure are analyzed. On this basis, the finite element method is used to establish a threedimensional finite element model, which further analyzes the deformation and mechanical characteristics of the lining structure under different conditions of internal water pressure, geological conditions, and internal water pressure alongside geological conditions. Therefore, theoretical guidance and technical support for the lining structure design of long-distance pressurized water delivery culverts are provided.

\section{Introduction}

With the rapid development of the urban economy, the problem of urban water use is becoming increasingly serious. To solve this problem effectively, the transregional water transfer project is a flexible and reliable solution, and the pressure culvert is a common hydraulic structure in water diversion projects [1-3]. The safety performance of water delivery culverts depends on the quality of the lining to a great extent [4-6]. Therefore, it is necessary to evaluate the lining quality of long-distance pressure culverts.

In engineering practice, there are many methods to evaluate the lining quality of long-distance pressure culverts. One such treatment method is nondestructive testing which is an effective and widely used method to ensure the safety of tunnel, such as the ground penetrating radar (GPR) [7-9], the multichannel analysis of surface waves (MASW) $[10,11]$, the infrared thermography (IRT) [12-15], and the Rayleigh waves [16]. However, the results of nondestructive testing were different from the reality results in some special stratum conditions, and this illustrated that the method of nondestructive testing also presents some limitations. Although some engineers have found that some advanced equipment can help mitigate these problems, the higher cost of equipment and complex operation process make it difficult to popularize and apply. It is therefore of great engineering interest and necessity to find a new method which not only has superior performance to ensure the accuracy of the test results but also is less expensive and easy to operate.

This paper takes the lining of a pressure water conveyance culvert as the research object. As a typical case, a pressure culvert of a water supply project is selected to carry out structural in situ tests and numerical simulations. Based on the field monitoring data, the mechanical and deformation responses of the lining structure under external water and earth pressure are analyzed. On this basis, the finite element method is used to establish a three-dimensional finite element model, by which further analysis of the 
deformation and mechanical characteristics of the lining structure under the conditions of different internal water pressure and geological conditions plus internal water pressure is carried out.

\section{General Situation of a Water Supply Project}

The diameter of the pressure culvert of a main trunk line for a water supply project is $5.1 \mathrm{~m}$, the landform is the undulating platform and hill, the topography is high and low, the peak and valley are distributed alternately perpendicular to the line, there are two shallow river valleys and two gullies on the water delivery line, the buried depth ranges from $7 \mathrm{~m}$ to $18 \mathrm{~m}$, and the geological conditions of the overburden are mainly clay, mucky clay, and sandy gravel clay. To avoid the alternation of a double pipe and a single hole, a pipe with a $5.1 \mathrm{~m}$ inner diameter should be chosen, and the internal water pressure of these four pipes is 0.5 to $0.55 \mathrm{MPa}$. At present, the maximum internal diameter of PCCP pipe used in China is $4.0 \mathrm{~m}$, which is the culvert pipe project of SouthNorth Water Transfer Project. There is no engineering example in our country for PCCP pipe with $5.1 \mathrm{~m}$ inner diameter, and the equipment used to transport such large size whole precast culvert pipe depends on importing it, with the whole technology lacking and the uncertainty being too high. Therefore, the use of cast-in-place prestressed culverts in a project site with the corresponding implementation of all aspects and conditions is a practical method.

The maximum difficulty coefficient of cast-in-place prestressed culverts is 280.5 , and the maximum depth of soil cover is $18 \mathrm{~m}$. The total length of the prestressed culvert is $2265 \mathrm{~m}$, the inner diameter is $5.1 \mathrm{~m}$, and the round arch vertical wall is adopted outside. Top and sidewall thickness is $0.45 \mathrm{~m}$, the bottom thickness is $0.8 \mathrm{~m}$, and a high-strength nonbonding low-relaxation steel strand to provide culvert prestressed is used. The practical application of $5.1 \mathrm{~m}$ largescale cast-in-place concrete prestressed culverts is rare in China and is one of the major technical problems in the entire water supply project.

\section{Deformation Response of the Lining Structure under Stress Based on Monitoring}

To understand the deformation characteristics of the anchor steel strand, an anchor cable dynamometer, a fully distributed optical fiber, and a magnetic flux sensor were installed at different section positions of the culvert, and realtime monitoring of the tension effect on the prestressed steel strand was performed under three working conditions: pressure water (culvert water pressure gradually increased to $0.602 \mathrm{MPa}$ ), filling soil, and pressure water after soil filling (culvert water pressure gradually increased to $0.56 \mathrm{MPa}$ ).

\subsection{Tension Effect of Prestressed Steel Strand under Water Pressure}

3.1.1. Monitoring Situation of Anchor Cable Dynamometer. In the process of the water pressure test, the whole curve of 3 pairs (6 pieces) of anchor cable dynamometer with different sections of culvert pipe (sections 1 and 2) is shown in Figure 1. The test result of the anchor cable dynamometer shows that the water pressure of the culvert pipe increases gradually to $60.2 \mathrm{~m}$ head, and there is no obvious change in the prestress value of the anchorage end of the steel strand.

3.1.2. Monitoring of Fiber Bragg Grating Intelligent Steel Strands. During the water pressure test, valid data were detected on the ZGD1 and ZGD2 fiber smart steel strands at sections land 2 (Figure 2). The variation of prestressed steel strand increases with the increase of water head; the variation of tension prestress of steel strand from the upper part to the top of culvert pipe is larger than that of other parts, and the maximum value of section 1 is approximately $3.54 \mathrm{kN}$, and that of section 2 is approximately $10.2 \mathrm{kN}$. Generally, the tension of prestressed steel strands changes slightly.

3.1.3. Magnetic Flux Sensor Test Results. One cycle of (16) magnetic flux sensors was arranged, and the variation law of the effective tensioning prestress along the circumference of the steel strand under different water pressures was monitored. As shown in Figure 3, with increasing internal water pressure, the effective tension on the steel strand changes slightly. The effective tension curves of the $16.3 \mathrm{~m}$ and $60.2 \mathrm{~m}$ heads are basically matching. Compared with the curve when $100 \%$ tension was just reached, the effective prestress value of the steel strand at the bottom of the culvert pipe decreased greatly, while the effective prestress value of the steel strand above the middle of the culvert pipe decreased relatively slightly after approximately 4 months. As shown in Figure 4, under the condition of a $60.2 \mathrm{~m}$ water head, the effective prestress value of the steel strand along the circumferential path of the culvert pipe is small, and the tension increases to a maximum gradually along the path to the middle and upper parts of the culvert pipe. Then, along the path to the top of the culvert pipe, the tension gradually decreases to the minimum, and the variation law of the effective tension prestress basically shows the M-shaped law of left and right axis symmetry. The maximum effective tension at the lower part of the culvert is $112.0 \mathrm{kN}$, and the minimum effective tension at the top of the culvert is $84.6 \mathrm{kN}$.

\subsection{Tension Effect of Prestressed Steel Strands under Soil Filling Conditions}

3.2.1. Test Results of Anchor Cable Dynamometer. During the filling test, there are 3 pairs (6 pieces) of anchor cable dynamometers, among which the no. 1 anchor cable dynamometer can monitor the corresponding data, and its entire curve is shown in Figure 5. The test results of the anchor cable dynamometer show that the tensile prestress value of the anchor end of the steel strand basically does not change during the filling process of the prestressed culvert pipe. 


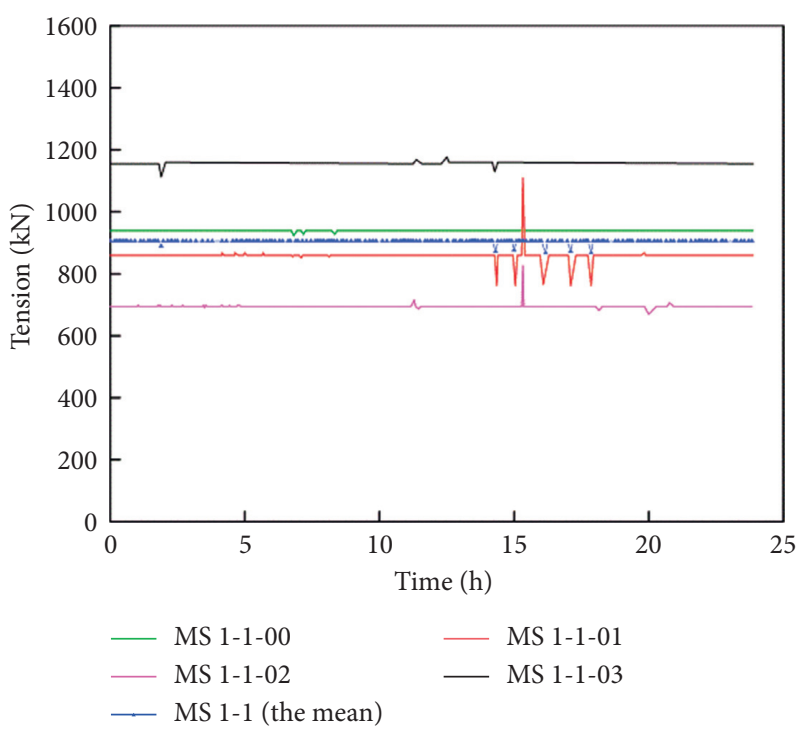

(a)

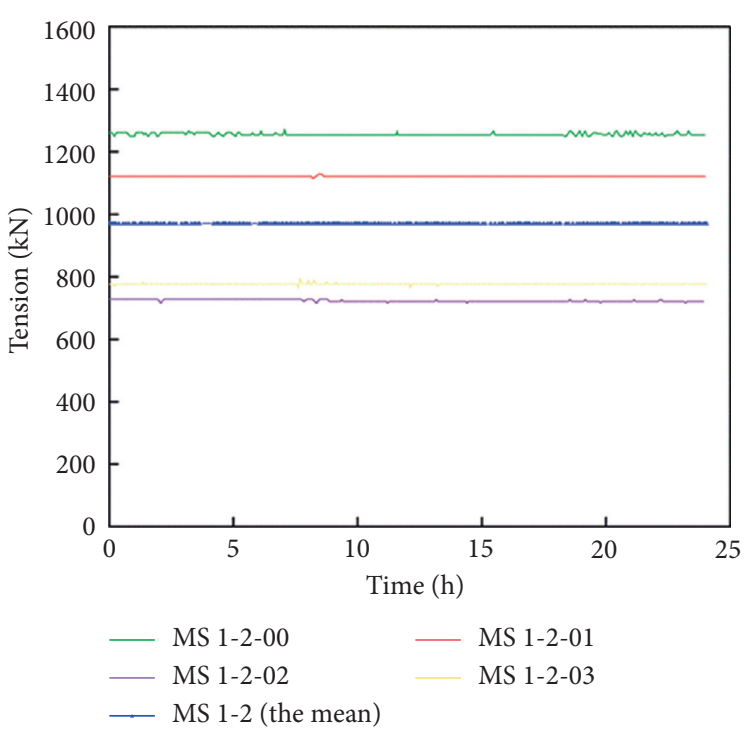

(b)

FIgURE 1: Test result curve of the anchor cable dynamometer in the water pressure test: (a) section 1; (b) section 2.

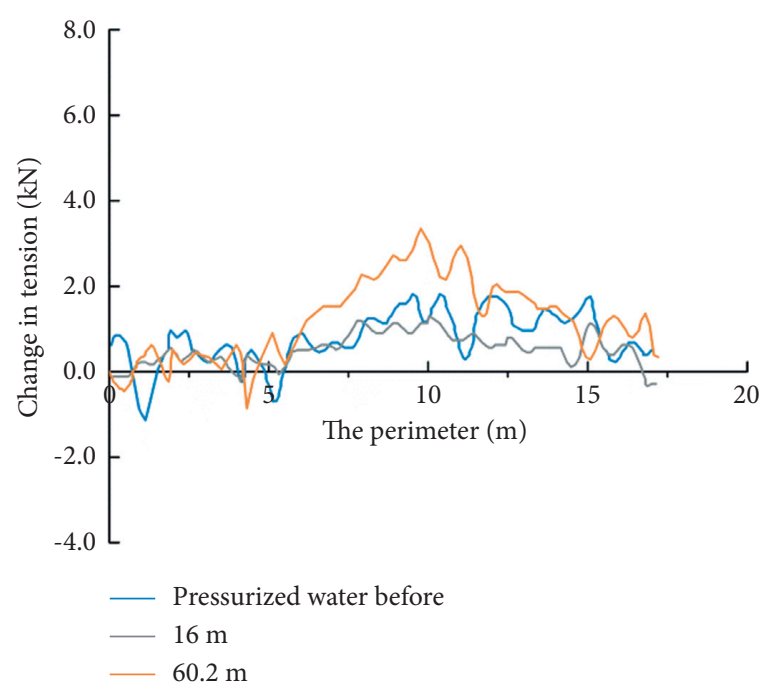

(a)

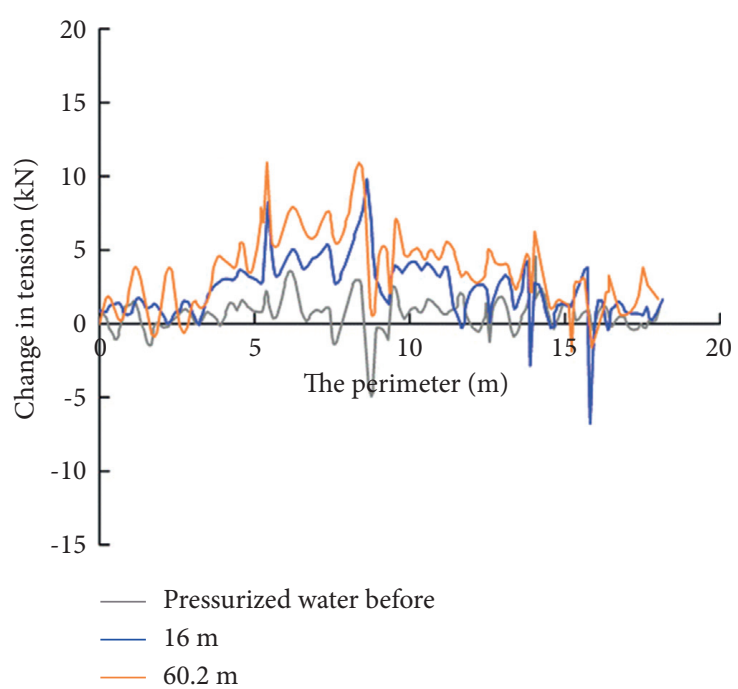

(b)

Figure 2: Test result curve of the distributed fiber intelligent steel strands during the section water pressure test: (a) section 1; (b) section 2.

3.2.2. Magnetic Flux Sensor Test Results. One ring (16 sensors) of magnetic flux was arranged to monitor the variation law of the effective prestressing force of the steel strand at different locations along the circumference under earth pressure after the filling is completed. As shown in Figure 6, the effective tension on the steel strand under the upper $13 \mathrm{~m}$ overburden pressure has no obvious change and basically matches the effective tension curve under the conditions of $16.3 \mathrm{~m}$ and $60.2 \mathrm{~m}$ head. Compared to the curve that just reached maximum tension, the effective prestressed value of the steel strand at the bottom of the culvert pipe decreases greatly, while the effective prestress value of the steel strand above the middle of the culvert pipe decreases relatively slightly. As shown in Figure 7, after the filling is completed, the effective prestress value of the steel strand along the circumferential path of the culvert pipe is small, and the tension increases to a maximum $(115.0 \mathrm{kN})$ gradually along the path to the middle and upper parts of the culvert pipe. Then, along the path to the top of the culvert pipe, the tension gradually decreases to the minimum $(94.3 \mathrm{kN})$, and the variation law of the effective tension prestress basically shows the M-shaped law of left and right axis symmetry. 


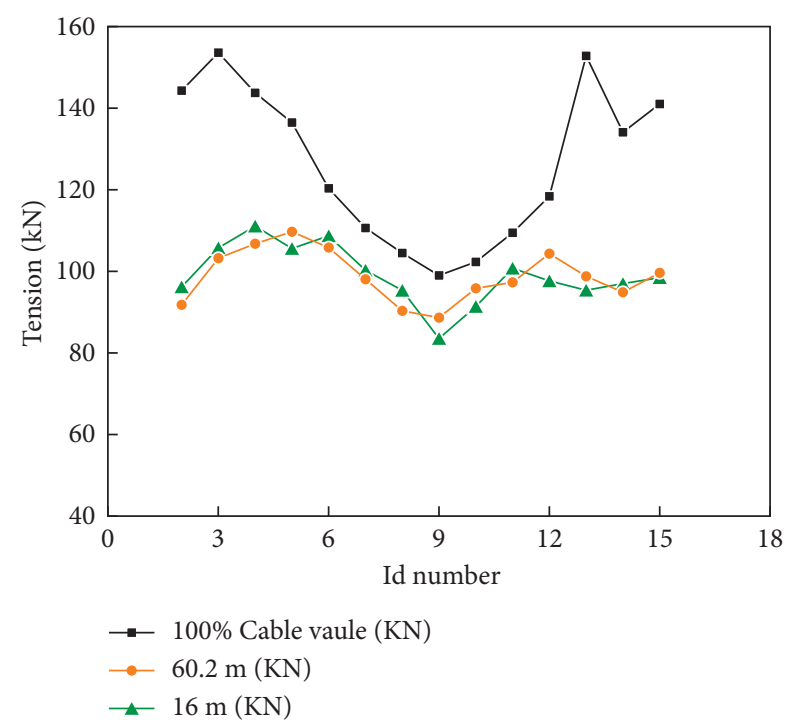

FIGURE 3: Test curve of the water pressure test of the magnetic flux sensor.

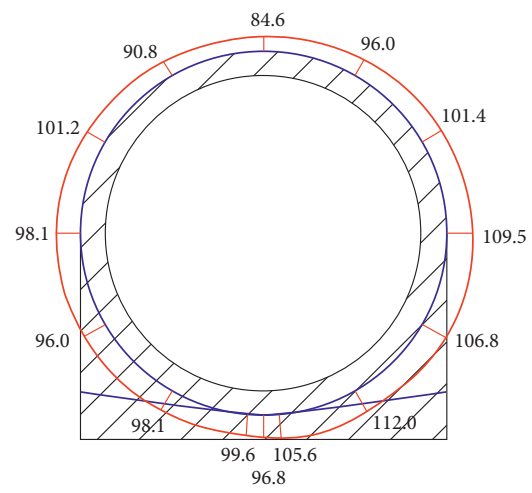

Figure 4: Water head test curve at $60.2 \mathrm{~m}$ in the water pressure test of the magnetic flux sensor $(\mathrm{kN})$.

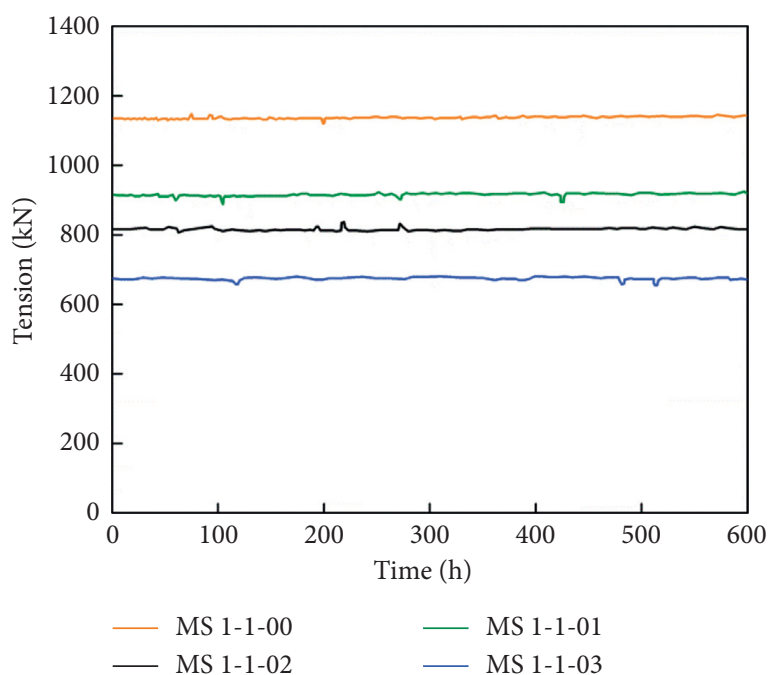

FIGURE 5: Test result curve of the anchor cable dynamometer in the soil filling test.

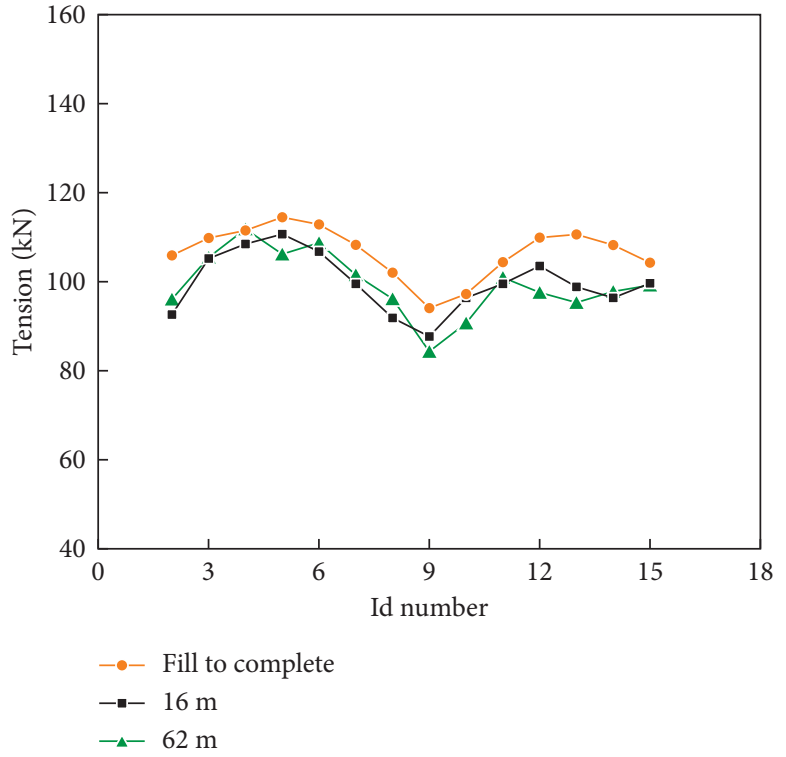

Figure 6: Test curve of the magnetic flux sensor filling test.

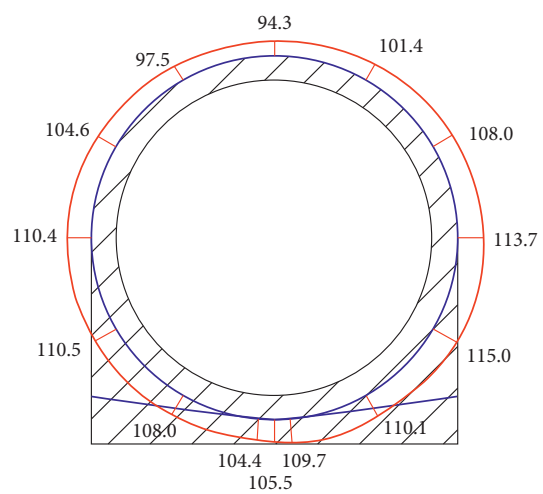

FIgURE 7: Test curve of the magnetic fluxsensor after soil filling $(\mathrm{kN})$.

\subsection{Tension Effect of Prestressed Steel Strand under Water Pressure after Filling}

3.3.1. Test Results of Anchor Cable Dynamometer. In the process of the water pressure test after filling, the whole curve of 3 pairs ( 6 pieces) of anchor cable dynamometers of different sections is shown in Figure 8. The test results of the anchor cable dynamometer show that during the process of water pressure of the culvert pipe, it gradually increased to a $56 \mathrm{~m}$ head after filling, and the tensile prestress value of the anchor end of the steel strand basically has no obvious change.

3.3.2. Magnetic Flux Sensor Test Results. One ring (16 magnetic flux sensors) was arranged to monitor the variation law of the effective prestressing force of the steel strand at different positions along the circumference under the condition of water injection and pressure again after the completion of soil filling. As shown in Figure 9, the effective tension on the steel strand changes slightly under the action 


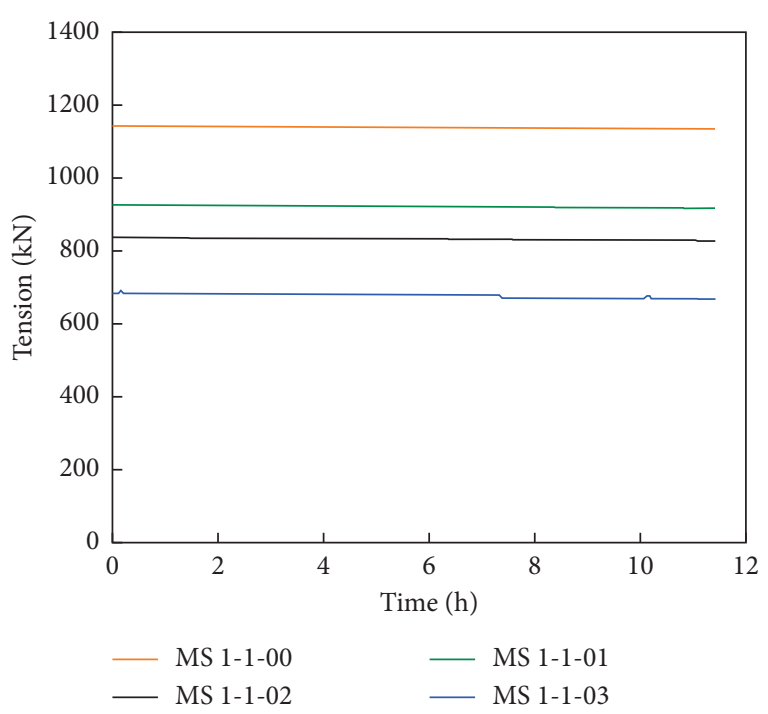

FIgURE 8: Test curve of the water pressure test process after soil filling by the magnetic flux sensor.

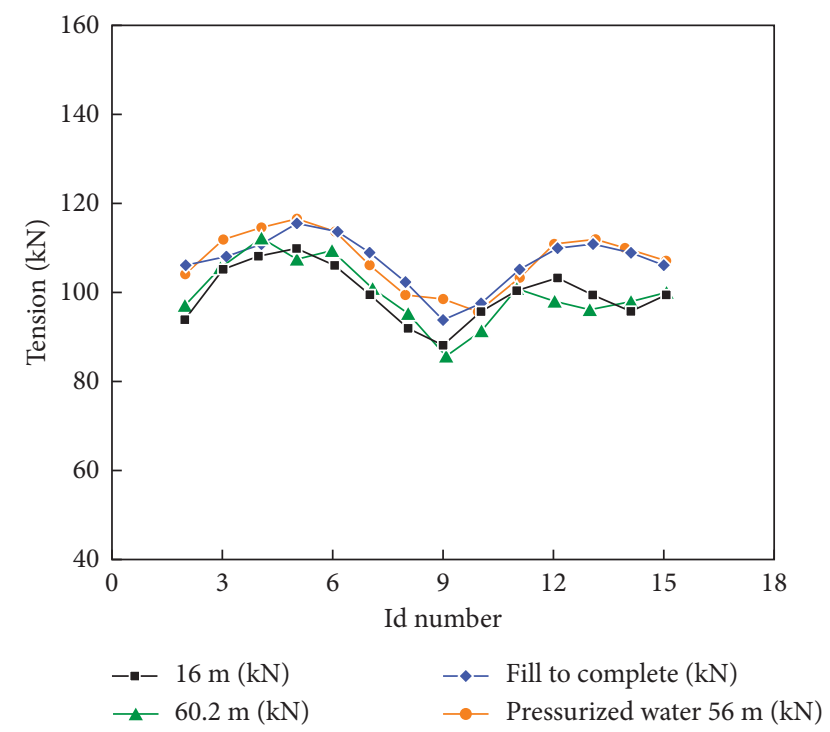

Figure 9: Test curve of the water pressure test process of the magnetic flux sensor after soil filling.

of water pressure after soil covering and basically matches the effective tension curve under the previous working conditions. As shown in Figure 10, at $56 \mathrm{~m}$ head of water condition after soil filling, the effective prestress value of the steel strand along the circumferential path of the culvert pipe is small, and in the middle and upper parts along the path to the culvert, the tension gradually increased to a maximum. Then, the effective prestress value tension gradually decreasing to a minimum, and the variation law of the effective tension prestress basically shows the $M$-shaped law of leftaxis and right-axis symmetry. The maximum effective tension in the middle and lower parts of the culvert pipe is $117.0 \mathrm{kN}$, and the minimum effective tension in the middle and upper parts of the culvert pipe is $96.5 \mathrm{kN}$.

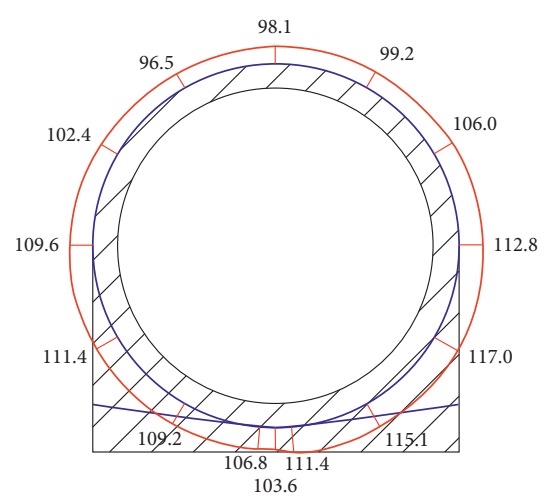

Figure 10: Water head test curve at $56 \mathrm{~m}$ in the water pressure test of the magnetic fluxsensor after soil filling $(\mathrm{kN})$.

3.4. Evaluation of the Tensile Effect on the Prestressed Steel Strand. The tensile force measured by the force meter is 953.8 $\mathrm{N}$ to $1065.3 \mathrm{~N}$, indicating that the tensile force of the six prestressed steel strands basically reaches the design value of $1171.8 \mathrm{kN}$. When the steel strand is locked, the tension at some measuring points is lost greatly, and the maximum loss is $273.1 \mathrm{kN}$. After the completion of strand tension, the effective prestress of the strand located at the bottom of the culvert pipe reaches the maximum and gradually decreases along the circumferential path of symmetry on both sides until the tension reaches the minimum at the top of the culvert pipe.

In the process of the water pressure test, with increasing water pressure, the size and distribution law of the effective tension prestress of the steel strand have no significant change, as shown in the results of the numerical simulation. Compared to the effective prestress distribution curve of the steel strand at the completion of tension, the effective prestress value of the steel strand at the bottom of the culvert pipe decreases greatly, but the effective prestress value of the steel strand above the middle of the culvert pipe decreases relatively slightly. Along the circumferential path of the culvert pipe, the effective prestress value at the bottom of the steel strand is small. Along the path to the middle and upper parts of the culvert pipe, the tension gradually increases to the maximum, and then along the path to the top of the culvert pipe, the tension gradually decreases to the minimum, and the effective prestress basically shows an M-shaped change law.

\section{Analysis of the Lining Structure Based on the 3D Nonlinear Numerical Simulation}

The lining structure is analyzed based on a $3 \mathrm{D}$ nonlinear numerical simulation. When establishing the model, the axis direction is divided according to the spacing of the prestressed steel strand. When the spacing is $300 \mathrm{~mm}$, the axis direction is divided into 40 sections, that is, the length of a culvert pipe is $12 \mathrm{~m}$. In the finite element model, the $Z$ axis is the vertical direction, the $X$ direction pointing to the flow direction is positive, and the $Y$ direction is the horizontal axis, and the $X$ direction is the vertical $X$ axis, satisfying the 


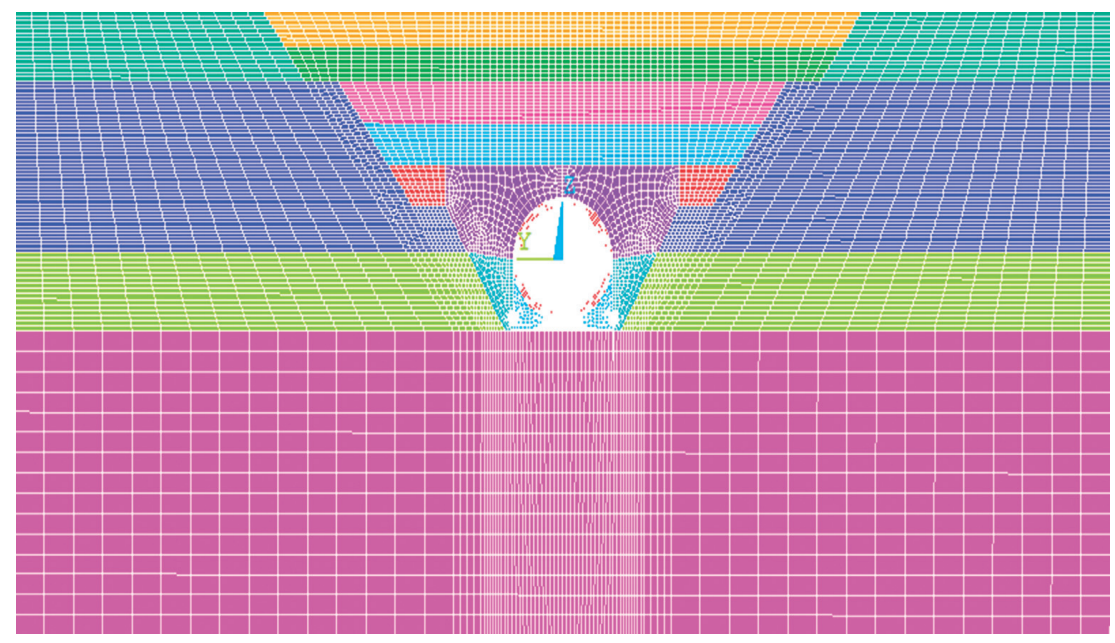

FIGURE 11: Overall model of the soil layer and prestressed culvert pipe.

right-hand rule. In the finite element model, prestressed steel strands, steel bars, and concrete are modeled separately by solids, and the contact mechanical action of steel strands on concrete is considered. During the finite element analysis, the prestress of the steel strand is applied by the cooling method, and the overall model is shown in Figure 11.

4.1. Working Condition of Calculation. According to the construction, tension, and actual operation of the cast-inplace prestressed culvert, the calculation conditions are set as follows: water filling pressure condition $(0.55 \mathrm{MPa}$ water pressure); filling condition; and water filling pressure condition (0.55 $\mathrm{MPa}$ water pressure).

4.2. Calculating Parameters. The physical and mechanical parameters of the rock and soil mass are listed in Table 1. The elastic modulus of the steel strand is $1.95 \mathrm{e}^{5} \mathrm{MPa}$, Poisson's ratio is 0.3 , and linear expansion coefficient $\alpha=2 \mathrm{e}^{-5}$. The elastic modulus of concrete is $3.25 \mathrm{e}^{4} \mathrm{MPa}$, and Poisson's ratio is 0.167 .

\subsection{Analysis of Calculation Results}

4.3.1. Water Filling Conditions. Figures 12 and 13 show the calculation results of applying internal water pressure by filling water without overlying soil.

When an internal water pressure of $0.55 \mathrm{MPa}$ is applied, the prestressed culvert expands outward as a whole. Due to the stiffness difference between the vertical and horizontal directions of the structure itself, the deformation of the structure is mainly in the horizontal direction, and the maximum incremental deformation value is $0.595 \mathrm{~mm}$, which appears at the waist of the arch. The maximum vertical deformation occurs from the shoulder to the waist of the arch, with a magnitude of $0.169 \mathrm{~mm}$. The incremental deformation of the structure presents a symmetry which corresponds to the structure itself. Under the influence of structural expansion and deformation, the concentration of compressive stress at the bottom of the circular culvert decreases, and the level of circumferential compressive stress decreases to a certain extent. The maximum compressive stress occurs at the anchor groove. At the same time, the maximum tensile stress value decreased to $2.211 \mathrm{MPa}$, which still appeared at the overlapping part of the steel strand at the bottom of the circular culvert. Compared to the field-measured monitoring data, the variation law is consistent with the actual situation.

4.3.2. Working Condition of the Filled Soil. After the completion of $18 \mathrm{~m}$ filling, the newly filled soil will settle itself and cause further settlement due to additional stress caused by its dead weight on the soil of the lower test foundation pit. Figure 14 shows the total deformation of the prestressed culvert structure due to soil settlement. To further determine the deformation and structural stress variation characteristics of concrete culvert structures caused by bearing earth pressure, the "follow-up" deformation caused by soil subsidence is deducted. Here, the center of the bottom of the concrete culvert is taken as the fixed point to obtain the relative deformation of the concrete culvert structure with respect to the fixed point, as shown in Figure 15.

Figure 16 shows that because the upper filled soil formed the asymmetric structure of the culvert soil pressure, the vertical earth pressure was large, and the horizontal earth pressure was small. Combined with the concrete culvert structure stiffness asymmetry, the vertical stiffness and horizontal stiffness were small, thus causing shrinkage in concrete culvert structure and presenting vertical direction and horizontal expansion deformation characteristics. The value of vertical convergent deformation was significantly greater than that of horizontal convergent deformation. The horizontal expansion deformation is $1.0 \mathrm{~mm}$. The maximum vertical relative deformation is $2.4 \mathrm{~mm}$, which appears in the vault and is vertically downward. Compared to the fieldmeasured monitoring data, the variation law is consistent with the actual situation. 
TABle 1: Physical and mechanical parameters of rock mass.

\begin{tabular}{lccc}
\hline Calculated parameters & Clay & Mud clay & Clay containing sand and gravel \\
\hline Deformation modulus $(\mathrm{MPa})$ & 14 & 16 & 20 \\
Cohesive force $(\mathrm{kPa})$ & 10 & 10 & 3 \\
Angle of internal friction $\left({ }^{\circ}\right)$ & 14 & 14 & 20 \\
Saturated unit weight $\left(\mathrm{kN} / \mathrm{m}^{3}\right)$ & 19.1 & 19.1 & 19 \\
\hline
\end{tabular}

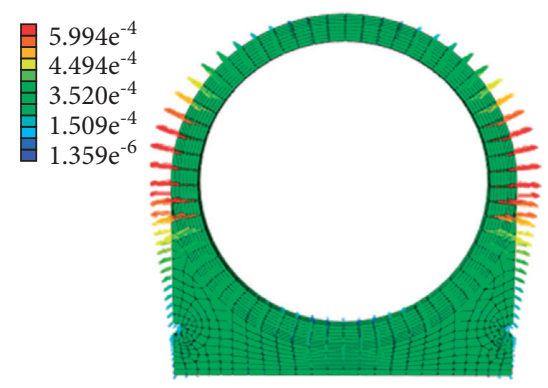

(a)

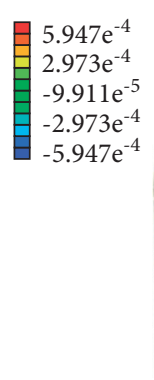

(b)

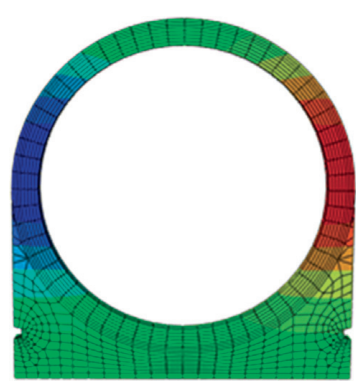

b)
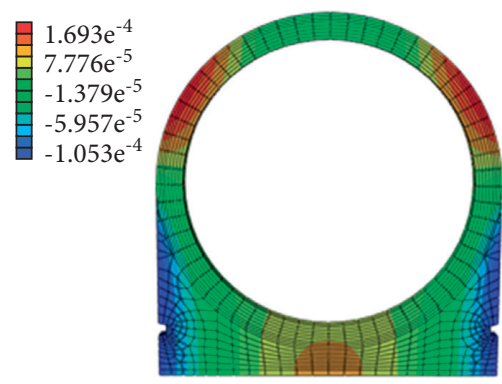

(c)

FIGURE 12: Incremental deformation of the prestressed culvert structure: (a) deformation vector diagram; (b) horizontal deformation; (c) vertical deformation.

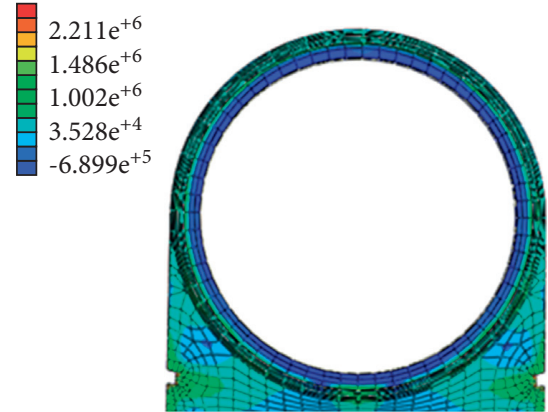

(a)

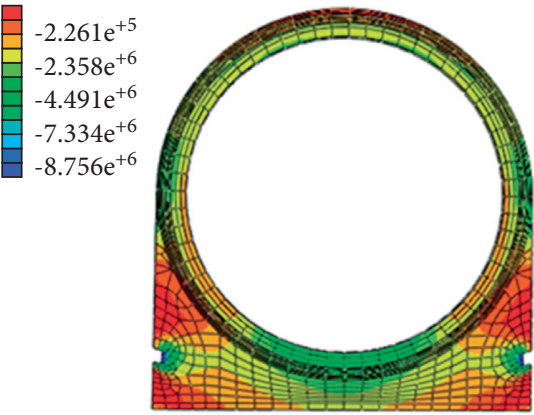

(b)

FIgURE 13: Stress cloud diagram of the prestressed culvert structure: (a) maximum principal stress; (b) minimum principal stress.

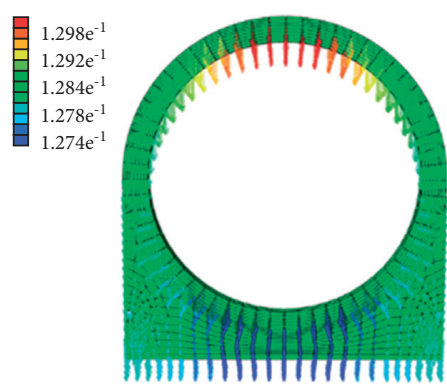

(a)

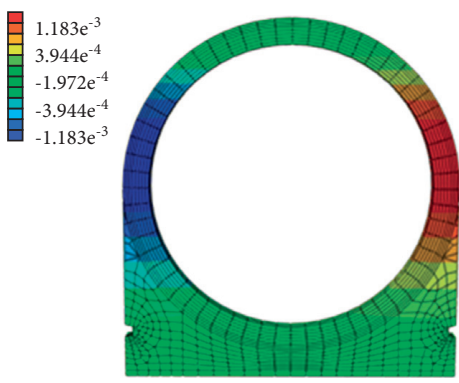

(b)
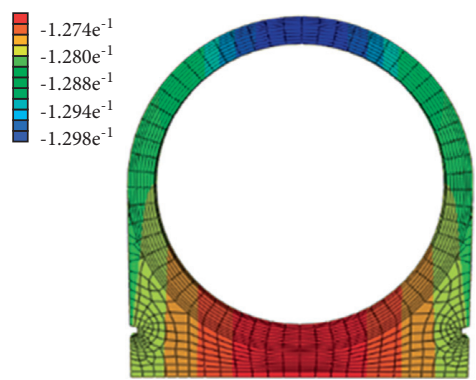

(c)

FIGURE 14: Incremental deformation of prestressed culvert structure: (a) deformation vector diagram; (b) horizontal deformation; (c) vertical deformation.

4.3.3. Water Filling Condition after Soil Filling. The internal water pressure is simulated on the basis of the filling condition. Figure 17 shows the incremental deformation cloud diagram of the prestressed culvert under internal water pressure. The horizontal expansion deformation of the prestressed culvert is larger than the vertical expansion deformation due to the asymmetry of the stiffness of the culvert and the soil pressure. The deformation morphology 


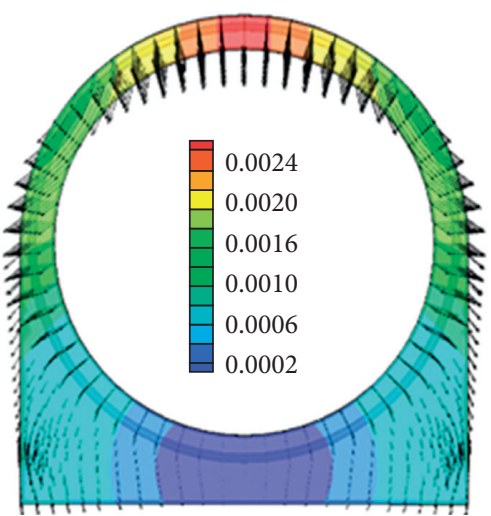

(a)

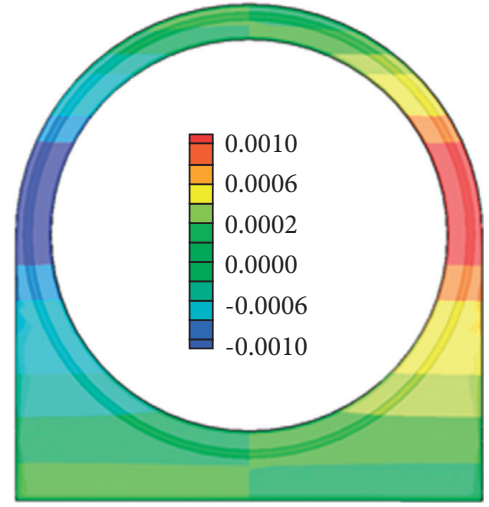

(b)

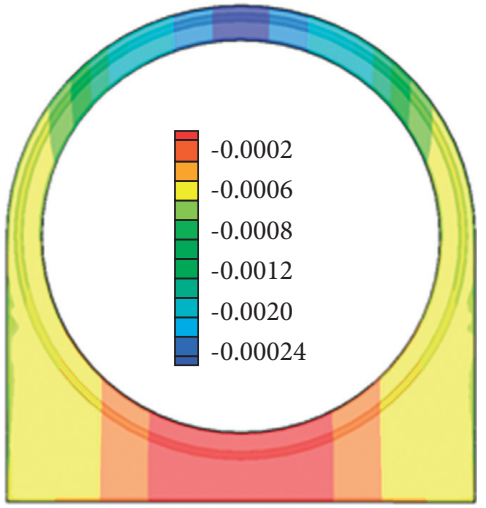

(c)

FIGURE 15: Relative deformation cloud diagram of prestressed culvert structure: (a) resultant displacement; (b) horizontal displacement; (c) vertical displacement.

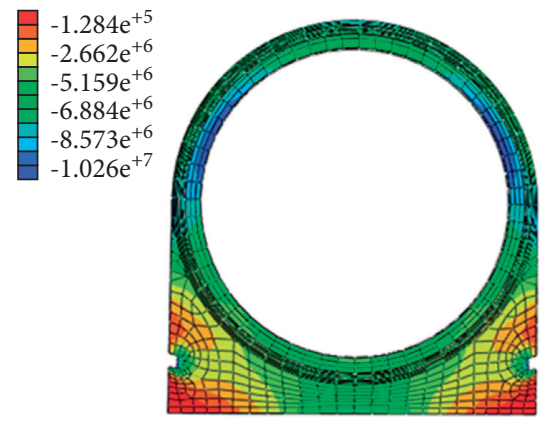

(a)
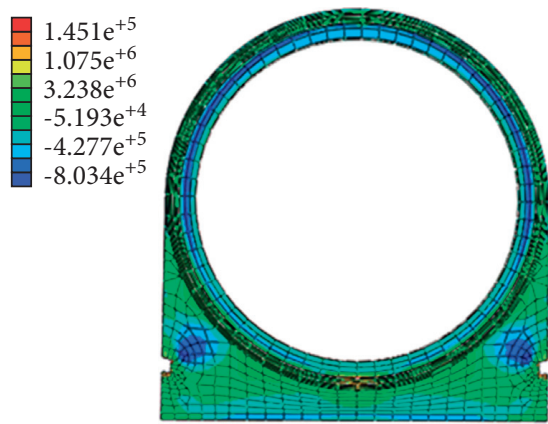

(b)

FIGURE 16: Stress cloud diagram of the prestressed culvert structure: (a) maximum principal stress; (b) minimum principal stress.

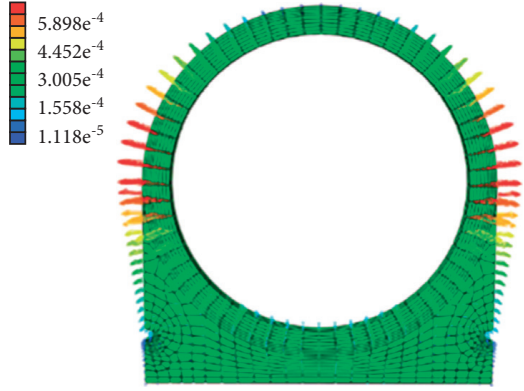

(a)
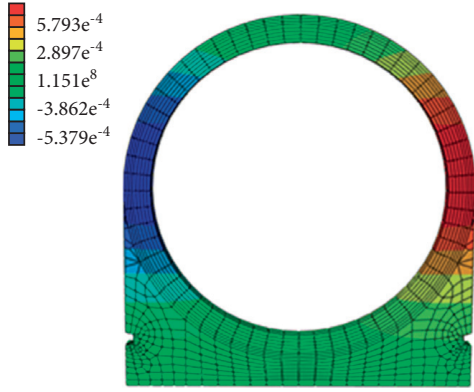

(b)
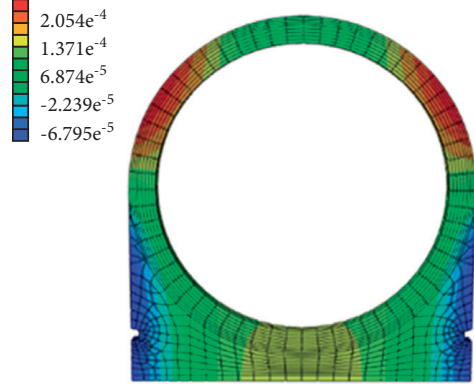

(c)

FIGURE 17: Incremental deformation of the prestressed culvert structure: (a) deformation vector diagram; (b) horizontal deformation; (c) vertical deformation.

shows symmetry consistent with the structure. The deformation near the arch waist of the prestressed culvert is the largest and is mainly in the horizontal direction, and the maximum horizontal deformation value is $0.579 \mathrm{~mm}$. The deformation diminishes from the arch waist to the vault. The maximum vertical displacement occurred on the left and right arch shoulders with a magnitude of $0.205 \mathrm{~mm}$. Compared to the field-measured monitoring data, the variation law is consistent with the actual situation. Affected by the expansion deformation of the culvert pipe caused by internal water pressure, the circumferential compressive stress of the prestressed culvert decreases, and the maximum compressive stress is $8.775 \mathrm{MPa}$. At the same time, the tensile stress at the bottom and outside of the prestressed culvert increases, and the maximum value for it is $1.529 \mathrm{MPa}$ (Figure 18). 


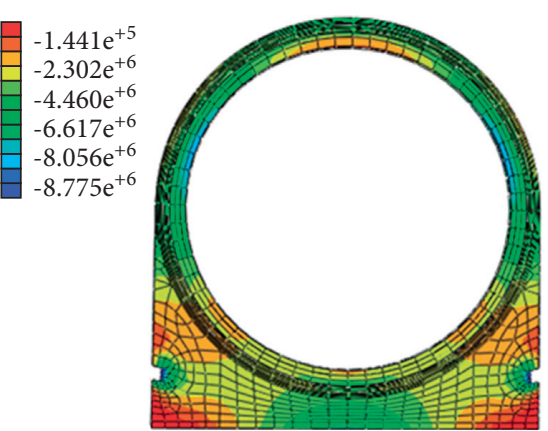

(a)

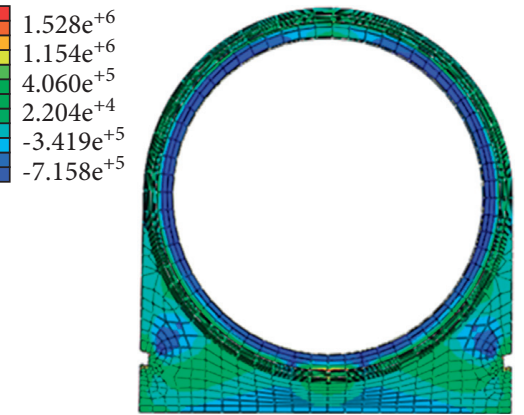

(b)

Figure 18: Stress cloud diagram of the prestressed culvert structure: (a) maximum principal stress; (b) minimum principal stress.

\section{Conclusion}

(1) During the in situ test of the culvert lining, a magnetic flux sensor, a fully distributed fiber optic strain gauge, a fiber grating strain gauge, and a vibrating string anchor cable dynamometer were used to measure the tension of the steel strand. The test conditions included tension, water pressure, soil filling, and water pressure after soil filling, all of which required $-30^{\circ} \mathrm{C}$ cold weather and $+35^{\circ} \mathrm{C}$ hot weather. The test results show that the testing effect of the magnetic flux sensor is obviously better than the distributed optical fiber strain gauge and fiber Bragg grating strain gauge. The test data of vibrating string anchor cable are relatively stable under different conditions, but they can only test the tension at the locking end of steel strand.

(2) Three-dimensional finite element analysis results show that the upper filled soil formed the asymmetric structure of the culvert soil pressure, with the vertical earth pressure being big and the horizontal earth pressure being small. Moreover, the stiffness asymmetry is causing shrinkages in the concrete culvert structure and presents a vertical direction and a horizontal expansion deformation characteristic. The value of the vertical convergent deformation is significantly greater than that of horizontal convergent deformation. The horizontal expansion deformation is $1.0 \mathrm{~mm}$. The maximum vertical relative deformation is $2.4 \mathrm{~mm}$, which appears in the vault and is vertically downward. Compared with the field-measured monitoring data, the variation law is consistent with the actual situation.

(3) The deformation near the arch waist of the prestressed culvert is the largest and is mainly in the horizontal direction, and the maximum horizontal deformation value is $0.579 \mathrm{~mm}$. The deformation diminishes from the arch waist to the vault. The maximum vertical displacement occurred on the left and right arch shoulders with a magnitude of $0.205 \mathrm{~mm}$. Compared to the field-measured monitoring data, the variation law is consistent with the actual situation.

\section{Data Availability}

The datasets generated and/or analyzed during the current study are available from the corresponding author upon reasonable request.

\section{Conflicts of Interest}

The authors declare that they have no conflicts of interest.

\section{Acknowledgments}

This study was supported by the Natural Science Foundation of Hunan Province (2019-JJ-50336 and 2021JJ60063) and the Major Water Conservancy Science and Technology Project of Hunan Province (XSKJ2018179-01).

\section{References}

[1] A. Moawad, J. A. Mccorquodale, and G. Abdel-Sayed, "Hydraulic loading in culvert inlets," Canadian Journal of Civil Engineering, vol. 22, no. 6, pp. 1104-1112, 1995.

[2] B. L. McGuigan and A. J. Valsangkar, "Earth pressures on twin positive projecting and induced trench box culverts under high embankments," Canadian Geotechnical Journal, vol. 48, no. 2, pp. 173-185, 2011.

[3] O. S. Oshati, A. J. Valsangkar, and A. B. Schriver, "Performance of two cast-in-place box culverts under high embankments," Canadian Geotechnical Journal, vol. 49, no. 12, pp. 1331-1346, 2012.

[4] J. Vaslestad, A. Madaj, and L. Janusz, "Field measurements of old brick culvert slip lined with corrugated steel culvert," Transportation Research Record: Journal of the Transportation Research Board, vol. 1892, no. 1, pp. 227-234, 2004.

[5] B. P. Tullis and D. S. Anderson, "Slip-lined culvert inlet end treatment hydraulics," Journal of Irrigation and Drainage Engineering, vol. 136, no. 1, pp. 31-36, 2010.

[6] S. J. Korky, M. Najafi, J. E. Syar, and V. K. Nandyala, "Evaluation of literature on design and performance of spray applied pipe linings for renewal of culverts and drainage structures," Pipelines 2019: Multidisciplinary Topics, Utility Engineering, and Surveying, pp. 75-83, American Society of Civil Engineers, Reston, VA, 2019.

[7] A. Atef, T. Zayed, and A. Hawari, "Multi-tier method using infrared photography and GPR to detect and locate water leaks," Automation in Construction, vol. 61, pp. 162-170, 2016. 
[8] T. Thitimakorn, N. Kampananon, N. Jongjaiwanichkit, and S. Kupongsak, "Subsurface void detection under the road surface using ground penetrating radar (GPR), a case study in the Bangkok metropolitan area, Thailand," International Journal of Geo-Engineering, vol. 7, no. 1, pp. 1-9, 2016.

[9] D. H. Chen and A. Wimsatt, "Inspection and condition assessment using ground penetrating radar," Journal of Geotechnical and Geoenvironmental Engineering, vol. 136, no. 1, pp. 207-214, 2010, 207-214.

[10] M. Karray and G. Lefebvre, "Détection des cavités sous les pavages par l'analyse modal des ondes de Rayleigh (MASW)," Canadian Geotechnical Journal, vol. 46, no. 4, pp. 424-437, 2009.

[11] M. Le Feuvre, A. Joubert, D. Leparoux, and P. Côte, "Passive multi-channel analysis of surface waves with cross-correlations and beamforming. Application to a sea dike," Journal of Applied Geophysics, vol. 114, pp. 36-51, 2015.

[12] C. Meola, G. M. Carlomagno, and L. Giorleo, "The use of infrared thermography for materials characterization," Journal of Materials Processing Technology, vol. 155-156, pp. 1132-1137, 2004.

[13] C. Ibarra-Castanedo and X. Maldague, "Pulsed phase thermography reviewed," Quantitative Infrared Thermography Journal, vol. 1, no. 1, pp. 47-70, 2004.

[14] C. Ibarra-Castanedo, J. R. Tarpani, and X. P. V. Maldague, "Nondestructive testing with thermography [J]," European Journal of Physics, vol. 34, no. 6, pp. 91-109, 2013.

[15] D. Kalhor, S. Ebrahimi, R. B. Tokime et al., "Cavity detection in steel-pipe culverts using infrared thermography," Applied Sciences, vol. 11, no. 9, p. 4051, 2021.

[16] J. Sun, X. Chen, and X. Tian, "Engineering infrastructure nondestructive testing with Rayleigh waves: case studies in transportation and archaeology," Journal of Geophysics and Engineering, vol. 4, no. 3, pp. 268-275, 2007. 